\title{
Indicadores de sustentabilidade ambiental para o território quilombola Serra da Guia/SE
}

Indicadores de sustentabilidade ambiental são ferramentas que possibilitam análise detalhada das formas de uso e ocupação do solo, auxiliando na gestão e proposição de estratégias de planejamento territorial mais eficazes para promover a sustentabilidade ambiental. Neste sentido, o objetivo desse trabalho foi de mensurar indicadores de sustentabilidade ambiental para a território quilombola Serra da Guia no município de Poço Redondo/SE. Para tanto, foram consultados 111 moradores do quilombo Serra da Guia e elaborados mapas de uso e ocupação do solo, mapas de áreas de APP e conflito de uso do solo no ano de 2020 para seleção de indicadores ambientais, além de serem realizadas visitas in loco para análise das ações antrópicas na área. Os resultados indicam que o quilombo possui índice de sustentabilidade ambiental regular, $(0,4167)$ e que os indicadores com os piores valores foram 'Destinação de Resíduos Sólidos', 'Saneamento' e '\% APP' seguidos da 'Paisagem'. Notou-se ainda, que é evidente o conflito de uso e ocupação do solo nas áreas destinadas à preservação, de maneira que o uso causador dos conflitos mais comuns se refere aos da pastagem e do solo exposto, demonstrando a presença de atividade antrópica nas áreas legalmente protegidas. Assim são necessárias políticas de recuperação das áreas de proteção ambiental, pois as APP são importantes instrumentos para a conservação dos ecossistemas.

Palavras-chave: Território Quilombola; Preservação; Ambiente.

\section{Environmental sustainability indicators for the quilombola territory of Serra da Guia/SE}

Environmental sustainability indicators are tools that enable detailed analysis of the forms of land use and occupation, assisting in the management and proposition of more effective territorial planning strategies to promote environmental sustainability. In this sense, the objective of this work was to measure environmental sustainability indicators for the Serra da Guia quilombola territory in the municipality of Poço Redondo/SE. To this end, 111 residents of the Serra da Guia quilombo were consulted and maps of land use and occupation, maps of APP areas and conflict of land use in the year 2020 were drawn up to select environmental indicators, in addition to on-site visits to analysis of anthropic actions in the area. The results indicate that the quilombo has a regular environmental sustainability index $(0.4167)$ and that the indicators with the worst values were 'estination of Solid Waste', 'Sanitation' and '\% APP' followed by 'Landscape'. It was also noted that the conflict in the use and occupation of land in areas intended for preservation is evident, so that the most common conflictive use is grazing and exposed soil, demonstrating the presence of anthropic activity in legally protected areas. Thus, policies for the recovery of these areas of environmental protection are necessary, as APPs are important instruments for the conservation of ecosystems.

Keywords: Quilombo Territory; Preservation; Environment.

Topic: Planejamento, Gestão e Políticas Públicas Ambientais

Reviewed anonymously in the process of blind peer.
Received: 03/02/2021

Approved: 27/02/2021
Flávia Regina Sobral Feitosa (iv)

Universidade Federal de Pernambuco, Brasil http://lattes.cnpq.br/1348596925096357 http://orcid.org/0000-0002-9366-8899 flaviareginasf@gmail.com

Cláudio Jorge Moura de Castilho (D) Universidade Federal de Pernambuco, Brasil http://lattes.cnpq.br/0107090882082784

http://orcid.org/0000-0003-3609-9914 claudiocastilho44@gmail.com

\section{Gregório Guirado Faccioli (it)}

Universidade Federal de Sergipe, Brasil http://lattes.cnpq.br/4563644185421346

http://orcid.org/0000-0003-2666-3606 gregorioufs@gmail.com
Referencing this:

FEITOSA, F. R. S.; CASTILHO, C. J. M.; FACCIOLI, G. G.. Indicadores de sustentabilidade ambiental para o território quilombola Serra da Guia/SE. Revista Ibero Americana de Ciências Ambientais, v.12, n.2, p.625-641, 2021. DOI: http://doi.org/10.6008/CBPC2179$\underline{6858.2021 .002 .0054}$ 


\section{INTRODUÇÃO}

Os indicadores são instrumentos técnicos capazes de retratar aspectos pontuais da dinâmica socioambiental, cuja integração e evolução permitem a compreensão e o acompanhamento da realidade analisada (PHILLIPI JUNIOR et al., 2011), no âmbito do contexto histórico-territorial abordado. Figuram-se como parâmetros para comparar e avaliar os territórios em vários aspectos de sua dimensão e complexidade, uma vez que realizam um recorte técnico, social, econômico, cultural e ambiental do objeto analisado (MINAYO et al., 2000). Entretanto, para que esses sejam retratos fidedignos da realidade existencial de grupos tão específicos, como os quilombolas, é necessário conhecer o cotidiano e lugar de troca dos sujeitos, de modo que os aspectos relacionados aos níveis socioeconômicos e ambientais interferem invariavelmente nas condições de vida dos territórios em epígrafe.

Os territórios dos quilombolas são considerados símbolos históricos de resistência social, por terem padecido, durante séculos, com a omissão estatal e, por conseguinte, terem vivenciado o conjunto das carências mais basilares de uma sociedade exacerbadamente desigual e injusta arraigada na escravidão como um dos seus pilares básicos. A desassistência representa-se pelas disputas agrárias em torno das áreas ocupadas, bem como pela falta de infraestrutura e investimentos públicos que não são providos pelo Estado em diversos setores dos referidos territórios (saúde, meio ambiente, educação, habitação, saneamento básico, acesso aos bens e serviços públicos, etc.). Com isso, os quilombolas ainda sofrem em função do isolamento físico/social, assim como dos preconceitos de raça, crença e falta de informação acerca de seus direitos.

Ao fazerem uso de técnicas de sensoriamento remoto e geoprocessamento, os indicadores ambientas constituem-se ferramentais indispensáveis ao monitoramento da dinâmica de uso e ocupação do solo e da delimitação das áreas de APP, uma vez que muitos quilombos não são devidamente estudados devido à dificuldade de acesso a esses espaços. Destarte, pode-se aferir como o espaço está organizado e verificar em que medida há um uso racional da terra e dos recursos naturais que ela contém, pois, o manejo adequado do solo evita a erosão e degradação ambiental. Além disso, é possível analisar em que medida a disposição dos elementos da paisagem no território gera situações propícias à vulnerabilidade dos quilombolas. Ressalta-se ainda, que existem áreas em que o levantamento e monitoramento devem ser constantes, como as Áreas de Reserva Legal (ARL) e Preservação Permanente (APP), uma vez que a cobertura vegetal protege o ambiente contra os efeitos erosivos e a lixiviação do solo, auxiliando na regulação do fluxo hídrico que impacta diretamente na fauna e flora locais (ROCHA et al., 2019).

O artigo 30, inciso II da Lei 12.651/12 (Código Florestal) define APP como "área protegida, coberta ou não por vegetação nativa, com a função ambiental de preservar os recursos hídricos, a paisagem, a estabilidade geológica e a biodiversidade, facilitar o fluxo gênico de fauna e flora, proteger o solo e assegurar o bem-estar das populações humanas" (BRASIL, 2012). Desta forma, as legislações das APP, no meio rural, auxiliam na manutenção dos recursos naturais, biodiversidade, processos ecológicos, na proteção dos corpos hídricos do assoreamento, da contaminação por poluentes, conservando habitats indispensáveis para a 
fauna e flora. Essas áreas são protegidas pelo Código Florestal (artigo 4o da Lei 12.651/2012) e estão localizadas nos cursos d'água, represas, lagos naturais, ao redor de nascentes, em topo de morros e em declividades maiores que 45ㅇ (BORGES et al., 2011; OLIVEIRA et al., 2018).

A Reserva Legal $(\mathrm{RL})$ corresponde à área situada no interior da propriedade ou posse rural com vegetação nativa, de uso público ou privado, destinada à conservação e ao uso sustentável dos recursos naturais. Na região Nordeste, a RL corresponde a $20 \%$ da área total do imóvel rural; em outras regiões, o percentual oscila em consonância com a localização e intensidade de ocupação da área. As áreas de RL são calculadas a partir das informações sobre a propriedade/posse do imóvel inseridas no Cadastro Ambiental Rural (CAR), sendo obrigatória para todos os imóveis rurais públicos ou privados (artigo 29, da Lei $n^{\circ}$ 12.651/2012). Mediante aprovação do órgão competente do SISNAMA, a Reserva Legal trata-se de uma ferramenta que poderá ser instituída em regime de condomínio ou coletiva entre as propriedades rurais, sendo este o caso dos territórios quilombolas (art. 68 do ADCT, art. $3^{\circ} \S$ único e art. 55 da Lei n¹2.651/2012 e $\S 2^{\circ}$ do Decreto $n^{\circ} 4.887 / 2003$ ), servindo inclusive como condição para o acesso às políticas públicas e seus instrumentos, tais como guia de transporte animal, licenciamentos, dentre outros (BRASIL, 2012).

Percebe-se, portanto, que essa ferramenta constitui um instrumento criado também para a regularização fundiária das propriedades, de modo que algumas lacunas na sua operacionalização podem impactar em riscos aos quilombos, considerando que existem deficiências do Sistema Nacional de Cadastro Ambiental (SICAR), referente aos territórios de uso coletivo, por exemplo. Desta forma, mesmo o Governo Federal orientando que o cadastramento do quilombo seja realizado apenas nas áreas ocupadas pelas famílias quilombolas e não de todo o território de uso tradicional e declarado, a comunidade negra repudia esse entendimento e defende que o CAR para os territórios quilombolas leves em consideração a área de uso tradicional e coletiva, considerando o direito de autorreconhecimento, logo todo o território e não apenas as áreas de moradia. Pois, entende-se que todas as conquistas legislativas que dizem respeito aos territórios quilombolas devem ser respeitadas quando da elaboração do CAR (CONAQ, 2020).

Logo, o estudo considerou a área total do quilombo para cálculo da reserva legal, por ser essencial que esses povos declarassem seus territórios, sem constrangimento, como ocorre com os demais produtores rurais. Além disso, eventuais divergências, com sobreposição de cadastros, só servirão para evidenciar a existência da disputada territorial e, que a partir de então, deve-se buscar mecanismos de enfrentamento ao real problema fundiário, principalmente nas áreas dos Povos e Comunidades Tradicionais (PCT).

Em geral, os territórios quilombolas mantêm preocupação com a sustentabilidade e conservação dos recursos naturais, face à relação intrínseca que mantém com sua forma de perceber e viver o mundo. Desse modo, são necessárias as políticas públicas para os mundos rural e urbano que forneçam condições para que os agricultores possam assimilar tecnologias simples e de baixo custo, apropriadas para uso e conservação do solo, a fim de que se alcance não só a sustentabilidade ambiental, mas a sustentabilidade cultural, uma vez que a terra tem um valor material e simbólico para os quilombolas (RIBEIRO et al., 2018).

Diante do acima exposto, o presente artigo tem por objetivo mensurar indicadores de sustentabilidade ambiental para o território quilombola Serra da Guia/SE, a partir da análise da paisagem, 
das áreas de preservação permanente (APP), com base nos dados coletadas in loco e no mapa de conflito de uso do solo da área.

\section{METODOLOGIA}

\section{Área de Estudo}

A comunidade Serra da Guia localiza-se a $42 \mathrm{Km}$ de Poço Redondo/SE, na microrregião sergipana "Sertão do São Francisco" a 187 km da capital Aracaju/SE, na região sul daquele município, fazendo parte do complexo Serra Negra, numa área contínua de resquícios de mata tropical, com espécies arbóreas de até 15 metros de altura, possuindo orquídeas do tipo Labiata (IBGE, 2016). O quilombo está situado no Semiárido, numa área de risco de desertificação do bioma caatinga, cenário que paulatinamente se agrava, sobretudo, pelo desmatamento visando à conquista de áreas para a agropecuária. As principais atividades econômicas da região são: a agricultura (produção de milho, feijão e mandioca) e a pecuária (criação de bovino, ovinos, equinos, caprinos e suínos). Com alto índice de analfabetismo (38\%), $60 \%$ da população se autodenominando negra e 79\% dos seus habitantes vivendo com um ou menos de um salário mínimo (FRIZEIRO, 2016).

Os quilombolas do Serra da Guia possuem área territorial de 9.013,18 hectares, a qual foi validada por decreto de desapropriação publicado em 22 de novembro de 2012, englobando no seu território os Povoados Pé de Serra, São Clemente, Salgadinho, Jacaré, Caximbeiro e Olaria. Entretanto somente 340,08 hectares de terra não são titulados. O quilombo possui 187 famílias cadastradas junto ao INCRA e desde abril de 2018 , esses povos que, realmente, formam uma comunidade foram beneficiados com a capacidade de inclusão de até 200 famílias quilombolas no Sistema Nacional de Reforma Agrária do INCRA (SIPRA), tendo assim acesso facilitado a uma série de créditos e programas de fomento implementados pelo órgão (INCRA, 2018).

O quilombo Serra da Guia apresenta infraestrutura precária, sem pavimentação, equipe de saúde da família, água encanada, saneamento básico. A área compreende o ponto mais elevado do território sergipano atingindo 750 metros de altitude. Entretanto, contemplar esse local de beleza inestimável, não é tarefa fácil, são $15 \mathrm{~km}$ de estrada de chão, o que lhe confere o status de ser umas das comunidades mais isoladas do conjunto dos quilombos sergipanos. Ressalta-se ainda, que a comunidade conta com uma liderança forte que articula doações e políticas públicas para o quilombo, Dona Josefa da Guia. Ela é parteira, líder comunitária, rezadeira, benzedeira e, apesar de não saber ler e escrever, presta auxílio a várias pessoas que a procuram em busca de cura, conselho espiritual e cuidados de saúde (NEVES, 2016), o que se acha significativamente vinculado à cultura dos povos em epígrafe.

\section{Obtenção e análise dos dados}

Os indicadores selecionados compreendem os referentes à dimensão ambiental, escolhidos em função da sua essencialidade à proteção do meio ambiente, ao uso dos recursos naturais e à degradação ambiental, atributos indispensáveis tanto para a qualidade de vida das presentes e futuras gerações como 
para a conservação dos ecossistemas locais. Os dados ambientais utilizados para mensuração dos indicadores foram obtidos das entrevistas realizadas com 111 moradores do quilombo Serra da Guia, da elaboração do mapa de uso do solo e áreas de APP confeccionado pelo Arc GIS. O critério de inclusão para participar do estudo foi: ser quilombola, maior de 18 anos, e entrevistar apenas um morador por família. A coleta de dados ocorreu de janeiro de 2019 a março 2020 e o projeto de pesquisa que originou o presente artigo foi submetido ao Comitê de Ética e Pesquisa com Seres Humanos da Universidade Federal de Pernambuco, através da plataforma Brasil, parecer no de 2.632.398; tendo, posteriormente, recebido a sua aprovação. O número de entrevistados foi escolhido aleatoriamente, a partir da fórmula de Barbetta (2008), conforme Equação 1:

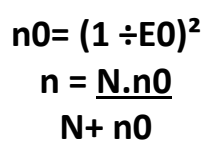

Onde:

$\mathbf{N}=$ número de famílias n0 = aproximação do número da amostra E0 $=$ erro tolerável $=0.06$ (probabilidade de acerto em 94\%). $\mathbf{n}=$ amostra

Dessa forma, a pesquisa apresentou um erro experimental dentro da faixa aceitável (6\%) e considerou como $\mathrm{N}=187$, que o número total de famílias quilombolas cadastrados no Sistema de cadastrados oficiais do INCRA em 2018.

Optou-se por selecionar os indicadores: 'Destinação de Resíduos Sólidos', 'Saneamento' e 'Uso de Defensivos Agrícolas', pelo potencial danoso que o descarte e/ou despejo inadequados desses elementos causam ao solo, à água, à saúde ambiental e, consequentemente, à integridade humana. Enquanto que, o indicador 'Paisagem' foi escolhido por ser imprescindível para auferir o impacto da ação humana sobre a biodiversidade.

E por fim, o 'Percentual de Reserva Legal' e de 'Áreas de Preservação Permanente' nos auxiliam a observar os locais que sofreram pressões decorrentes da forma de uso do solo, ou os que possibilitam uso mais sustentável da terra (Quadro 1). Ressalta-se ainda, que, para compreender e analisar a paisagem dos quilombos, utilizou-se como recurso a interpretação dos mapas de uso do solo, a observação in loco, para perceber os processos de ocupação demográfica e os principais tipos e distribuição dos cultivos/vegetação nativa, identificando as APP e a dinâmica de ocupação do solo da comunidade Serra da Guia/SE.

O mapa de uso do solo e o de localização dos quilombos foram elaborados a partir dos dados do atlas digital de Sergipe, da SRH/SEMARH/SE. Os shapes foram fornecidos pela Organização Não Governamental ONG-MapBiomas (MAPBIOMAS, 2019) e os dados dos quilombos cedidos pela Fundação Cultural Palmares (BRASIL, 2020). Para mensurar os indicadores "Paisagem" e "Percentual de Reserva Legal" foram confeccionados mapas de uso e ocupação do solo e valorado a qualidade da paisagem com base na metodologia de Sobral et al. (2012) e Sobral et al. (2015).

O mapa de uso da terra foi obtido a partir da classificação não supervisionada do processamento de bandas do satélite Sentinel, disponível no site USGS (earthexplorer.usgs.gov), de 15 de abril de 2020 para Serra da Guia com especificação de menos de $10 \%$ de cobertura de nuvens. Apesar da classificação não ter 
sido supervisionada, ela foi assistida pela prévia classificação de uso da terra fornecida pelo Atlas Digital de Sergipe, e de algumas outras características como recurso mineral, poço tubular, localidades, nascentes, hidrografia, rodovia estadual e lagos e reservatórios, bem como pelo acesso ao Google Earth Pro, cuja resolução da imagem foi de $5 \mathrm{~m}$, permitindo avaliação temporal mais simplificada.

Quadro 1: Indicadores da Dimensão Ambiental.

\begin{tabular}{|c|c|c|c|}
\hline \multicolumn{4}{|l|}{ DIMENSÃO AMBIENTAL } \\
\hline Indicadores & Parâmetros & Pontuação & Classificação \\
\hline \multirow{2}{*}{$\begin{array}{l}\text { IA1 } \\
\text { Destinação dos Resíduos Sólidos (RS) }\end{array}$} & \multirow{2}{*}{ Lei Federal 12.305/2010 } & Queimam e aterram $(0,0)$ & Insustentável \\
\hline & & Recolhido pelo serviço público $(1,0)$ & Sustentável \\
\hline \multirow{2}{*}{$\begin{array}{l}\text { IA2 } \\
\text { Saneamento }\end{array}$} & \multirow{2}{*}{ Lei $11.445 / 2007$} & Fossa seca ou séptica $(0,0)$ & Insustentável \\
\hline & & Rede de esgoto $(1,0)$ & Sustentável \\
\hline \multirow{3}{*}{$\begin{array}{l}\text { IA3 } \\
\text { Uso de Defensivos Agrícolas }\end{array}$} & \multirow{3}{*}{ Lei $7802 / 1989$} & Uso indiscriminado de defensivos agrícolas $(0,0)$ & Insustentável \\
\hline & & Uso controlado de defensivos agrícolas $(0,5)$ & Transição \\
\hline & & Sem defensivos agrícolas $(1,0)$ & Sustentável \\
\hline \multirow{3}{*}{$\begin{array}{l}\text { IA4 } \\
\text { Paisagem }\end{array}$} & \multirow{3}{*}{ Lei $12561 / 2012$} & Qualidade da Paisagem Ruim ou Péssima $(0,0)$ & Insustentável \\
\hline & & Qualidade da Paisagem Regular $(0,5)$ & Transição \\
\hline & & Qualidade de Paisagem Ideal e Boa $(1,0)$ & Sustentável \\
\hline \multirow{2}{*}{$\begin{array}{l}\text { IA5 } \\
\text { \% Reserva Legal }\end{array}$} & \multirow{2}{*}{$\begin{array}{l}\text { Lei } 12651 / 2012 \\
\text { Dec. } 4887 / 03\end{array}$} & Não atende a lei $(0,0)$ & Insustentável \\
\hline & & Atende a lei $(1,0)$ & Sustentável \\
\hline \multirow{2}{*}{$\begin{array}{l}\text { IA6 } \\
\text { \% Áreas de APP }\end{array}$} & \multirow{2}{*}{$\begin{array}{l}\text { Lei } 9985 / 2000 \\
\text { Lei } 12651 / 12\end{array}$} & Não atende a lei $(0,0)$ & Insustentável \\
\hline & & Atende a lei $(1,0)$ & Sustentável \\
\hline
\end{tabular}

O emprego do mapa de uso do solo objetivou especificar o processo de ocupação dos territórios quilombolas, bem como da disposição dos elementos da paisagem (Tabela 1) a fim de verificar em que medida eles contribuem para a sustentabilidade do quilombo, a partir da adaptação da metodologia de Sobral et al. (2012) e Sobral et al. (2015), de modo que o índice do componente 0 aponta para a existência de características menos sustentáveis da paisagem e 1 para a condição mais favorável do ponto de vista ambiental.

Tabela 1: Sistema de valoração do componente da paisagem.

\begin{tabular}{|l|l|l|l|}
\hline $\begin{array}{l}\text { Classes das } \\
\text { Paisagens }\end{array}$ & $\begin{array}{l}\text { Componentes } \\
\text { das Paisagens }\end{array}$ & $\begin{array}{l}\text { Índices dos } \\
\text { Componentes }\end{array}$ & Justificativa \\
\hline 1 & $\begin{array}{l}\text { Corpos } \\
\text { d'água/Vegetação densa }\end{array}$ & 1 & $\begin{array}{l}\text { Preservação dos RH, proteção das paisagens, biodiversidade, fluxo } \\
\text { gênico da fauna e flora e bem-estar humano. }\end{array}$ \\
\hline 2 & Vegetação não densa & 0,75 & $\begin{array}{l}\text { Estabilização do solo, redução do escoamento superficial, filtração do } \\
\text { ar, controle da radiação solar, dos ventos, umidade e o paisagismo. }\end{array}$ \\
\hline 3 & Cultivos agrícolas & 0.5 & $\begin{array}{l}\text { Menor potencial ecológico, mas essencial fator de sustentabilidade } \\
\text { socioeconômica. }\end{array}$ \\
\hline 4 & Pastagem & 0,25 & $\begin{array}{l}\text { Danos ambientais a paisagem com o pisoteio e a emissão de gases de } \\
\text { efeito estufa. }\end{array}$ \\
\hline 5 & Solo exposto & 0 & Compactação do solo e atividade insustentável para o quilombo. \\
\hline
\end{tabular}

Fonte: Adaptada de Sobral (2012) e Sobral et al. (2015).

A seguir foi calculado o índice de paisagem do quilombo por meio da fórmula proposta por Sobral (2016), conforme Equação 2:

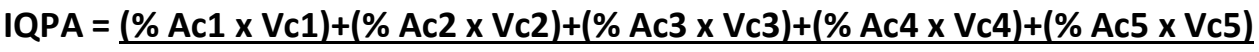
100 
e Sobral et al. (2015), conforme Tabela 2.

Tabela 2: Classificação da qualidade da paisagem do quilombo Serra da Guia/SE.

\begin{tabular}{ll}
\hline INTERVALO DE SUSTENTABILIDADE & CLASSIFICAÇÃO \\
\hline $0,80<$ Índice $\leq 1,0$ & Ideal \\
$0,60<$ Índice $\leq 0,80$ & Bom \\
$0,40<$ Índice $\leq 0,60$ & Regular \\
$0,20<$ Índice $\leq 0,40$ & Ruim \\
$0<$ Índice $\leq 0,20$ & Péssimo \\
\hline
\end{tabular}

Fonte: Adaptado de Silva et al. (2009); Sobral (2012) e Sobral et al. (2015).

Para mensurar o indicador 'Percentual de Áreas de APP', foi necessário confeccionar o Mapa de APP de Serra da Guia, o qual foi elaborado a partir dos shapes de nascentes, lagos, reservatórios e hidrografia disponibilizados no Atlas Digital de Sergipe, sendo para isso utilizada a ferramenta de raio de influência (buffer).

De acordo com o novo código florestal, lei 12.651 de 25 de maio de 2012, foram seguidas as especificações contidas nos artigos $4^{\circ}$ e $5^{\circ}$ da referida legislação, que são os raios de $15 \mathrm{~m}$ para nascentes, 05 metros, 08 metros, 15 metros e 30 metros para as respectivas categorias de lagos com até um, maior que um a dois, maior do que dois a 4, e maior do que quatro, e para $30 \mathrm{~m}$ para os rios (BRASIL, 2012). Os mapas de avaliação de APP de declividade foram obtidos no TOPODATA do INPE ${ }^{1}$ e reclassificados de acordo com as classes $(0-18 ; 18-25 ; 25-45 ;>45$ graus) quando houvesse.

Para a análise qualitativa, como os indicadores selecionados possuem naturezas distintas, eles foram agrupados numa matriz comum em que cada indicador foi valorado através de notas, que variavam de 0-1 pontos, o que permite realizar comparações entre os atributos (SOBRAL et al., 2012; MEDEIROS et al., 2018).

As mensurações dos indicadores embasaram-se em Sobral et al. (2015) e foram construídas a partir das observações in loco, registro dos diários de campo, entrevistas com os moradores dos quilombos, lideranças locais, legislações, mapa de uso e ocupação do solo. Os valores obtidos com a pontuação referente a cada indicador foram somados dentro do eixo da sustentabilidade ambiental e dividido pelo número total de indicadores desta dimensão. O resultado desse cálculo correspondeu ao Índice da dimensão ambiental analisada (Equação 3). Logo:

$$
\mathrm{ISA}=\frac{\mathrm{IA} 1+\mathrm{IA} 2+\cdots+\mathrm{IA} 6}{6}
$$

\section{RESULTADOS E DISCUSSÃO}

No Quilombo Serra da Guia participaram do estudo 111 pessoas, das quais 22,5\% (25) do sexo masculino e 77,5\% (86) do feminino. Em relação à faixa etária, prevaleceu a de 18-29 anos com 35,1\% (39) dos entrevistados.

\section{Destinação dos Resíduos Sólidos}

Na comunidade Serra da Guia, 71,1\% (79) dos entrevistados afirmaram ter coleta de resíduos sólidos

\footnotetext{
${ }^{1}$ http://www.webmapit.com.br/inpe/topodata/ 
e 28,9\% (32) disseram que esse serviço público não existe. Além disso, 30,6\% (34) dos participantes alegaram que o carro do lixo só passa uma vez ao mês, $29,7 \%$ (33) disseram que a coleta de resíduos acontece duas vezes por semana e 10,8\% (12\%) mencionaram que ela acontece uma vez por semana.

Apesar da existência desse serviço, provavelmente a irregularidade quanto à sua prestação possa contribuir com o modo inadequado com que a comunidade descarta seus resíduos sólidos, uma vez que $53,2 \%$ (59) dos entrevistados disseram que queimam e aterram seus resíduos e $46,8 \%$ (52) afirmaram que eles são recolhidos pelo serviço público municipal. Além disso, notou-se que nos dias em que não há adequada coleta de resíduos, os materiais são dispostos em terrenos baldios, ao ar livre, muitas vezes achando-se no entorno das residências, constituindo assim um instrumento de contaminação do solo, da propagação de vetores e de doenças para a própria comunidade.

Nesse sentido, Mucellin et al. (2008) já alertavam para o fato de que “[...] materiais sem utilidade se amontoam indiscriminada e desordenadamente, muitas vezes em locais indevidos como lotes baldios, margens de estradas, fundos de vale e margens de rios e lagos", causando severos danos à saúde da população. Dessa forma, o IA1 é considerado insatisfatório, não sendo pontuado, pois a destinação predominante é o descarte irregular. Registra-se que o tratamento incorreto de resíduos sólidos é uma prática bastante comum em regiões periféricas, sobretudo, onde a coleta de lixo é irregular. E como consequência dessa prática, tem-se prejuízos ambientais tanto para o solo quanto para a saúde humana.

\section{Saneamento}

Outra questão bastante problemática em Serra da Guia refere-se à do saneamento básico, uma vez que $100 \%$ (111) dos entrevistados afirmaram que não existe rede de esgoto na área e, que, portanto, os dejetos são destinados a uma fossa séptica (108), ou escorrem simplesmente a céu aberto (3).

De modo correlacionável, Santos et al. (2018) asseveram que:

No Brasil, o déficit no acesso aos serviços básicos atinge principalmente as populações negras e mais carentes que se concentram em quilombos, favelas, nas periferias das cidades e nas áreas rurais. A inexistência ou ineficácia de serviços de saneamento favorece ao agravamento da saúde e da qualidade de vida da população. Assim, a insuficiência de investimento neste setor interfere de forma negativa no sistema econômico, com gastos elevados para combater as enfermidades propagadas devido às condições sanitárias inadequadas. [...] Além de que, o saneamento básico e o consumo de água de qualidade são um direito de necessidade imediata, pois, sua ausência ou deficiência influencia negativamente no meio ambiente, na qualidade de vida e saúde da população. (SANTOS et al., 2018)

Enfim, segundo a Lei Federal no 11.445 (BRASIL, 2007), o saneamento básico é primordial para garantia da qualidade de vida dos brasileiros, de modo que a universalização do conjunto de serviços, infraestruturas e instalações operacionais de abastecimento de água potável, esgotamento sanitário, limpeza urbana, manejo de resíduos sólido e drenagem das águas pluviais devem ser assegurados a todo cidadão.

Pode-se perceber que as soluções tradicionais para o saneamento nesse quilombo ainda é a fossa séptica e a fossa rudimentar em função dos seus baixos custos, mesmo oferecendo risco à saúde humana. De acordo com a UNICEF, as fossas rudimentares (buracos no solo para coletar os excrementos humanos) 
são uma realidade para 7 milhões de brasileiros, mesmo não evitando a contaminação das águas, superficiais e subterrâneas. As fossas sépticas são unidades simples e baratas de tratamento do esgoto pelas quais são feitas a separação e transformação físico-química da matéria sólida, mas não promovem a reciclagem dos dejetos humanos (BRASIL, 2007; SANTOS et al., 2018), realidade inconcebível em pleno século XXI e contraditória com relação à Constituição Federal na qual o saneamento básico constitui direito de todo cidadão.

\section{Uso de Defensivos Agrícolas}

O adequado manejo agrícola contribui para melhorar a produção agropecuária e, consequentemente, para elevar os índices de desenvolvimento econômico. Em assim sendo, as principais estruturas de manejo agrícola encontradas no quilombo foram: currais, pocilga, cultivos de palmas, macaxeira, feijão, etc. A utilização dessas ferramentas conjuntamente com o uso sustentável do solo, asseguram a manutenção dos quilombos nos seus territórios.

Para efeito da Lei 7802/1989 regulamentada pelo decreto 4.074/2002 no seu artigo 2으, são considerados agrotóxicos (defensivos agrícolas) e afins:

a) os produtos e os agentes de processos físicos, químicos ou biológicos, destinados ao uso nos setores de produção, no armazenamento e beneficiamento de produtos agrícolas, nas pastagens, na proteção de florestas, nativas ou implantadas, e de outros ecossistemas e também de ambientes urbanos, hídricos e industriais, cuja finalidade seja alterar a composição da flora ou da fauna, a fim de preservá-las da ação danosa de seres vivos considerados nocivos;

b) substâncias e produtos, empregados como desfolhantes, dessecantes, estimuladores e inibidores de crescimento; II

c) componentes: os princípios ativos, os produtos técnicos, suas matérias-primas, os ingredientes inertes e aditivos usados na fabricação de agrotóxicos e afins.

Percebe-se que, apesar dos defensivos agrícolas destinarem-se ao aumento da produtividade no campo e serem obrigados a atender às exigências de segurança da saúde humana e ambiental, o risco no momento de sua utilização é real, sendo imprescindível uma série de cuidados, a fim de minimizar o contato e possíveis contaminações do solo, água e danos a biodiversidade.

As roças quilombolas caracterizam-se pela diversidade de espécies e variedades de plantas cultivadas (mandioca, milho, feijão, arroz, legumes, verduras, temperos, frutas, etc.) que, diferentemente da monocultura extensiva, realiza uma produção livre de agrotóxicos e mantém o cuidado com o meio ambiente na medida em que continuam desempenhando suas práticas tradicionais de cultivo e criação de animais. Enfim, as relações agrícolas no quilombo são pautadas na relação de reciprocidade entre o agricultor e a terra, de modo que o sistema agrícola quilombola preza pela segurança alimentar e muitas vezes o espaço se configura como um guardião de um variado material genético (IANOVALI et al., 2018).

Percebeu-se que em Serra da Guia, 100\% dos entrevistados cultivam o solo sem uso de qualquer defensivo agrícola. Logo, o IA3 para o quilombo de Serra da Guia é considerado satisfatório, sendo pontuado com 1,0 ponto. A agricultura orgânica quando não utiliza produtos químicos, torna as plantas mais resistentes ao ataque de pragas e doenças, possibilita a rotação de culturas, evita a exposição a produtos nocivos à saúde 
do agricultor e do consumidor, reduzindo os impactos ambientais e preservando a biodiversidade (SOUZA et al., 2020). Além disso, a não utilização de agrotóxicos poderá agregar valor à produção orgânica do quilombo, pois os mesmos passam a possuir atributos diferenciais em termos de qualidade associados ao sabor e características dos alimentos, que remetem à tradição e a ritos culturais. Além disso, as técnicas de manejo agrícola das comunidades em epígrafe, caso sejam potencializadas, fortalecem a conservação e o uso sustentável da biodiversidade (NODARY et al., 2015).

\section{Paisagem}

O mapa de uso do solo em Serra da Guia apontou a existência de 5 classes de uso do solo: Corpos d'água, Vegetação nativa/densa, vegetação não densa, pastagem e solo exposto (Figura 1).

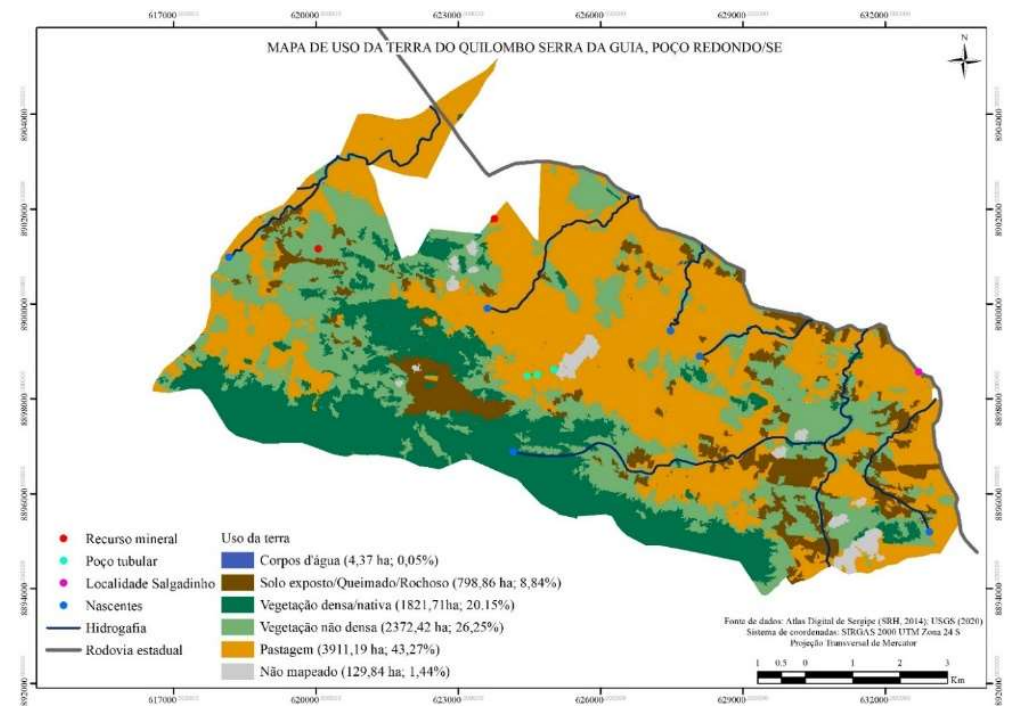

Figura 1: Mapa de uso do solo de Comunidade de Serra da Guia/SE.

Com relação à dimensão material da paisagem, que representa o território usado pelos povos quilombolas, percebe-se que em Serra da Guia a maior parte do solo (43, 27\% ou seja, 3922,19 hectares) é utilizada para a pastagem, uma atividade que além de provocar danos ao solo (compactação pelo pisoteio dos animais) e ao ambiente (emissão de gases poluentes), não tem o potencial de gerar autonomia e subsistência para as famílias quilombolas. Observou-se ainda a presença de grandes áreas destinadas ao cultivo de palma, a qual, por sua vez, serve para alimentar o gado. Possivelmente, os quilombolas tenham priorizado esse tipo de cultivo por disporem de um solo pouco fértil e com grande necessidade de manejo agrícola, tanto é que não foram detectadas áreas expressivas de agricultura na área.

Nesse sentido, os estudos de Frizeiro (2016) já detectavam que Serra Negra e Poço Redondo possuíam áreas sujeitas à desertificação (empobrecimento do solo, em geral relacionado a ações antrópicas sem o devido cuidado com a sustentabilidade do seu meio) com extenso comprometimento do ecossistema da caatinga devido ao desmatamento e à ocupação de áreas pela pecuária extensiva e que por isso, necessitaria de investimentos urgentes para recuperar as áreas atingidas e promover um desenvolvimento local sustentável para melhoria das trágicas condições de vida do sertanejo. Por isso, tenha-se encontrado baixo percentual de 'Corpos d'água' (0,05\%, 4,37 hectares) no local, sendo de fluxos temporários. 
Percebeu-se a presença de 20,15\% de áreas de vegetação nativa/densa (1821, 7 hectares) e 26, 25\% de vegetação não densa, ocupando uma quantidade expressiva do território (2372, 42 hectares). Isso demonstra a preocupação dos povos quilombolas em conservar as matas nativas e a biodiversidade, a despeito das intempéries climáticas.

Outra categoria observada no mapa de uso do solo refere-se à presença de solo exposto, correspondendo a $8,84 \%$ ( 798,86 ha) da área total do quilombo. Ressalta-se que, o solo exposto em Serra da Guia possui maior dificuldade de ser regenerado, pois foram decorrentes de queimadas, ou são rochosos. Inclusive, de 24 -29/12/ 2019, aconteceu um incêndio na área que perdurou por 05 dias. E mesmo que a comunidade tenha acionado o corpo de bombeiros, houve, segundo relatos do atual Presidente da Associação Quilombola da região, morosidade na contenção do fogo: 'A equipe do Corpo de Bombeiros foi acionada e nada pode ser feito, pois o caminhão não consegue ter acesso ao local. O fogo diminuía à noite, mas podia voltar a qualquer momento porque, na verdade, não tem nenhuma brigada para conter as chamas' (E3).

Dessa forma, a formação de uma brigada local de combate a incêndios, composta pelos próprios quilombolas, possibilitaria o planejamento e estruturação da área, inclusive com treinamento da população local para que, de maneira padronizada, segura e rápida, pudessem combater futuros focos de incêndio, minimizando os impactos negativos das queimadas no quilombo. Como a resposta do poder público é morosa, face à logística e à dificuldade de acesso aos locais, grandes têm sido os danos desses eventos para as comunidades tradicionais. Nesse sentido, morador local complementa: "O Corpo de Bombeiros chegou aqui na sexta-feira, mas disse que como o local era de difícil acesso, não poderiam fazer muita coisa e foram embora. É um absurdo, quase não tivemos apoio para a contenção das chamas, queimou por vários dias" (E4).

A seguir, os componentes da paisagem foram classificados de acordo com sua relevância para a sustentabilidade ambiental do quilombo, de modo que os elementos que obtiveram os melhores índices foram: corpos d'água e vegetação nativa/densa pontuada com 1,0; vegetação não densa valorada com 0,75 pontos; Cultivos Agrícolas $(0,50)$, Pastagem $(0,25)$ e Solo Exposto $(0,0)$, conforme Tabela 3.

Tabela 3: Cálculo do índice "Qualidade da Paisagem" do quilombo Serra da Guia/SE.

\begin{tabular}{|l|l|l|}
\hline COMPONENTE DA PAISAGEM & \% DAS ÁREAS DE CADA COMPONENTE & ÍNDICE DE QUALIDADE DA PAISAGEM \\
\hline Vegetação nativa/ densa & $0,05 \%+20,15 \%=20,20 \%$ & $20,20 \times 1=20,20$ \\
\hline Vegetação não densa & $26,25 \%$ & $26,25 \times 0,75=19,69$ \\
\hline Cultivos Agrícolas & $0 \%$ & $0 \times 0,5=0,0$ \\
\hline Pastagem & $43,27 \%$ & $43,27 \times 0,25=10,82$ \\
\hline Solo exposto & $8,84 \%$ & $8,84 \times 0,0=0,0$ \\
\hline Total & $\mathbf{9 8 , 5 6 \%}$ & $50,71 / 98,56=\mathbf{0 , 5 1 4}$ \\
\hline
\end{tabular}

Fonte: Adaptado de Sobral et al. (2012).

Ressalta-se que, o total não correspondeu a $100 \%$ pois $1,44 \%$ do território quilombola Serra da Guia/SE não se encontrava mapeado, logo, no índice de qualidade da paisagem, o valor total foi dividido pelo \% total de todas as áreas dos componentes da paisagem (98,56\%). Por fim, concluiu-se que o IA4 é regular, sendo classificada como de transição para a sustentabilidade do quilombo (0,5 pontos). 


\section{Percentual de Reserva Legal}

O quilombo Serra da Guia, mesmo tendo presenciado a expansão da atividade pecuária em sua área, respeita o limite legal de vegetação nativa conservada, possuindo 20,15\% (1821,7 hectares) de seu território ocupado por vegetação densa. Esse tipo de vegetação é um componente essencial à sustentabilidade dos quilombos, pois a baixa quantidade de cobertura vegetal prejudica a regularização dos fluxos hídricos, favorece a lixiviação e erosão do solo, prejudicando a fauna e flora, além de tornar o clima menos ameno (RIBEIRO et al., 2018). Além disso, as áreas de RL auxiliam na conservação e na reabilitação dos processos ecológicos, promovendo a conservação da biodiversidade, bem como abrigando e protegendo a fauna silvestre e a flora nativa, nos termos do Art. $2^{\circ}$, III, da Lei $n^{\circ} 12.651 / 2012$ (COSTA et al., 2014).

Ressalta-se ainda, que, de acordo com o artigo 54, da Lei n¹2.651/2012: “a manutenção da área da reserva legal na pequena propriedade ou posse rural, nos assentamentos e projetos de reforma agrária, quilombolas, reservas extrativistas e terras indígenas, poderão ser computados os plantios de árvores frutíferas, ornamentais ou industriais, compostos por espécies exóticas, cultivadas em sistema intercalar ou em consórcio com espécies nativas da região em sistemas agroflorestais" (BRASIL, 2012). Assim, o IA5 para Serra da Guia/SE foi considerado satisfatório $(1,0)$, pois respeita as determinações da legislação vigente.

\section{Percentual de Áreas de Preservação Permanente (\% APP)}

O Sistema Nacional de Unidades de Conservação da Natureza (SNUC) instituído pela Lei 9985 de 18/07/2000 (BRASIL, 2000) define, no seu artigo 15, as áreas de proteção ambiental como locais "de ocupação humana, dotados de atributos abióticos, bióticos, estéticos ou culturais especialmente importantes para a qualidade de vida e bem-estar das populações humanas, tendo por objetivo disciplinar o processo de ocupação e assegurar a sustentabilidade do uso dos recursos naturais".

A conservação das APP é fundamental para a gestão de bacias hidrográficas, e a estabilidade dos ciclos hidrológicos e biogeoquímicos, visando proporcionar condições de sustentabilidade à agricultura. Desse modo, intervenções nas APP para abertura de novas áreas agrícolas comprometerá, no futuro, a reposição de água nos aquíferos, a qualidade da água superficial e subterrânea, perda de solo, ameaças à saúde humana e degradação dos mananciais, além de comprometer a produção de alimentos, regulações dos ciclos naturais e, por conseguinte a manutenção do equilíbrio ecológico (TUNDISI et al., 2010; ROCHA et al., 2019). Foram elaborados mapas de APP a partir dos mapas de hidrografia e declividade, este último com base nas curvas de nível, por entender que as áreas são essenciais para a preservação da qualidade da paisagem

De acordo com o mapa de declividade do quilombo Serra da Guia, o local possui declividade de $100 \%$ (45) em áreas pontuais do quilombo (complexo Serra - Negra), embora existam pontos com declividade intermediária (Figura 02), acentuada em alguns trechos (25 a 45으. Em sendo assim, a vegetação nativa é primordial para controlar o escoamento de partículas, minimizando a degradação e erosão do solo. Além disso, as matas ciliares servem como barreiras naturais para evitar depósito de partículas nas calhas fluviais, 
mantendo o fluxo natural dos rios (ROCHA et al., 2019).

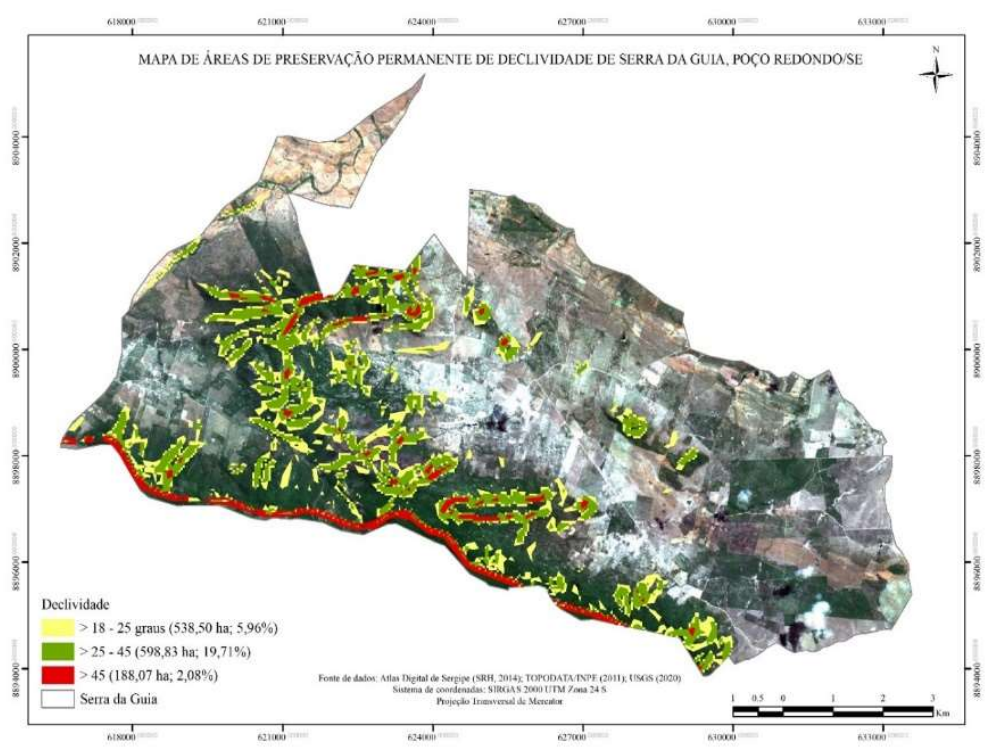

Figura 2: Mapa de Declividade da APP do Quilombo Serra da Guia /SE.

A área total da APP dos cursos d'água de Serra da Guia ocupa 3,435\% do território do quilombo. Percebe-se assim que, do total de APP onde deveria circundar as nascentes dos rios, apenas 0,05\% (0,43 hectares) é preservada (Figura 3). Essas áreas são essenciais para a manutenção da qualidade e quantidade de água das nascentes, influenciando diretamente no armazenamento da água subterrânea e no regime dos cursos d'água (PINTO et al., 2004).

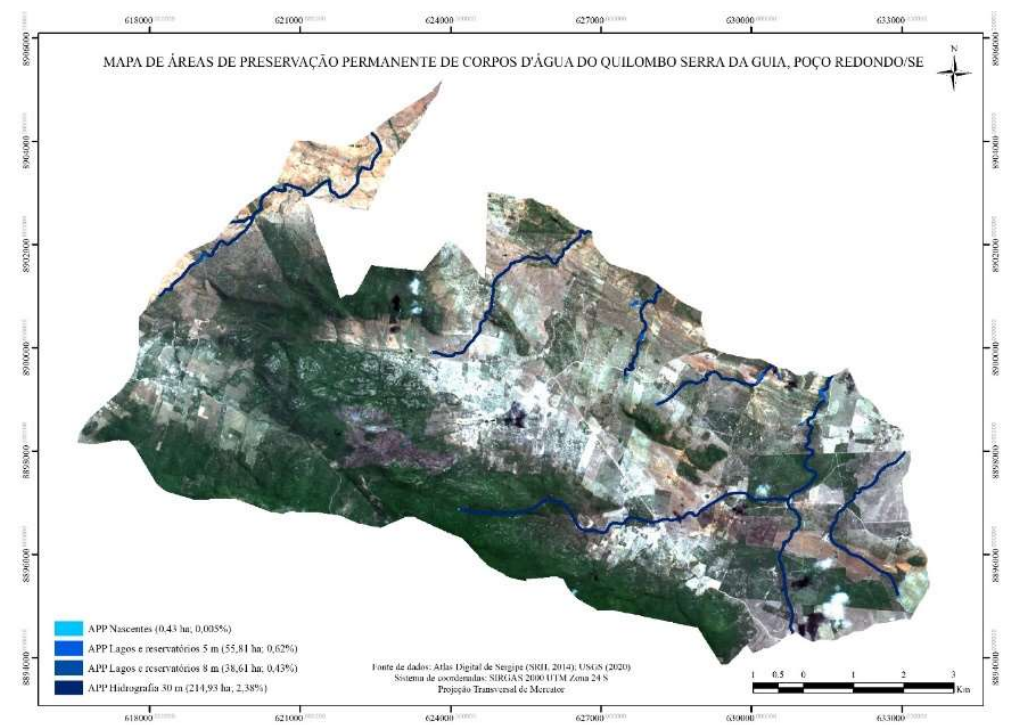

Figura 3: Mapa de APP de Corpos d'água do Quilombo Serra da Guia/SE.

As APP ao longo dos cursos d'água asseguram, portanto, a estabilização das margens dos rios, sendo relevantes no controle da qualidade da água por reduzirem a ocorrência de escoamento superficial, que pode causar erosão e arraste de nutrientes, produtos químicos e sedimentos para os cursos d'água (EUGENIO et al., 2011) da região.

Com relação a APP de lagos e reservatórios de 5 metros, percebeu-se que ela ocupa 0,62\% (55,81 ha) do território que deveria ser preenchido por esse tipo de vegetação; das APP que revestem os lagos e 
reservatórios de 8 metros, tem-se 0,43\% (38,6 ha). Por fim, a APP relacionada à hidrografia de 30 metros ocupa apenas $2,38 \%$ dos espaços em que deveriam ser encontradas.

Ao confrontarmos o mapa de uso do solo com as Áreas de Preservação Permanente, pôde-se analisar o conflito de uso da terra no interior da APP no quilombo de Serra da Guia (Figura 4).

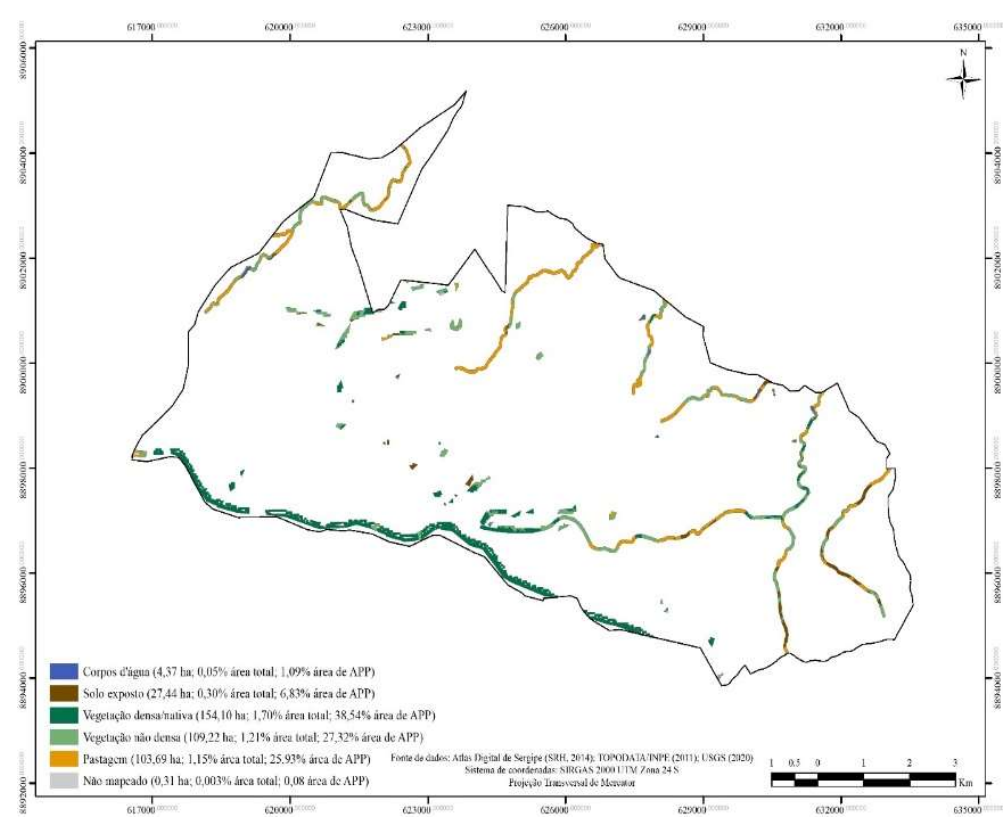

Figura 4: Conflito do uso do solo de APP do Quilombo Serra da Guia/SE.

Observa-se que as áreas de preservação correspondentes aos cursos d'água possuem somente 38,54 $\%(154,10$ ha) de suas áreas cobertas por vegetação nativa (classes de floresta e várzea) e 27,32\% de suas áreas preenchidas por vegetação não densa (109,22 ha). Assim, surge a necessidade de se alertar para a relevância de manter as áreas de vegetação ciliar conservadas, a fim de não provocar maior risco de assoreamento dos rios e nascentes.

Percebe-se a necessidade de se terem iniciativas voltadas para a restauração das matas ciliares, discutindo-se e planejando de forma participativa a melhor maneira de recuperar as áreas já degradadas, considerando as propostas de recuperação de maneira sustentável em termos ecológicos e sociais.

As áreas de pastagem ocupam 25,93\% das áreas que deveriam ser de APP dos cursos d'água e 1,15\% da área total. Essas somadas às APP ocupadas por solo exposto $(6,83 \%$ da área de APP, o que corresponde a 27,44 ha) totalizam $32,76 \%$ dos locais irregularmente destinados para a pecuária, considerando também as zonas altamente susceptíveis a danos ambientais. Enfim, os dados são alarmantes, visto que o inadequado modo de uso do solo acelera o processo de degradação/erosão e ferem frontalmente as determinações legais para preservação dos espaços, uma vez que os prejuízos oriundos da ação antrópica contribuem ainda mais para a perda/indisponibilidade das reservas hídricas e para o aumento contínuo de áreas susceptíveis à desertificação na região.

Diante deste cenário, o conjunto de "áreas protegidas" está ameaçado, não pela ausência de instrumentos legais, mas sim, pela falta de fiscalização, precária estrutura dos órgãos públicos, lacunas presentes na legislação, bem como a difícil aplicabilidade de políticas públicas de incentivo e efetivação de ações de conservação, gerando conflitos de uso do solo nesses espaços (IRIGARAY et al., 2013). Desta forma, 
o IA6 é considerado insatisfatório (pontuação 0,0).

\section{CONCLUSÕES}

Os índices ambientais retratados nesse estudo (destinação de resíduos sólidos, saneamento, uso de defensivos agrícolas, paisagem, \% áreas de APP e \% reserva legal) apontaram para uma sustentabilidade regular $(\mathbf{0 , 4 1 6 7 )}$ do quilombo Serra da Guia em Poço Redondo/SE.

Percebeu-se que, em Serra da Guia os indicadores ambientais que obtiveram os piores valores foram 'Destinação de Resíduos Sólidos', 'Saneamento' e '\% APP' (0,0), seguidos da 'Paisagem' (0,5). Assim, a mensuração de indicadores de sustentabilidade ambiental para a comunidade quilombola Serra da Guia pode se configurar como uma importante ferramenta a serviço do planejamento territorial, possibilitando a elaboração de estratégias para a conservação dos ecossistemas, além de ajudar a perceber quais características do território interferem na qualidade de vida dos quilombolas.

A ausência de políticas públicas básicas e efetivas em termos de salubridade ambiental teve influência direta nos índices, visto que há irregularidade na coleta de resíduos e precariedade na rede de esgotamento sanitário, levando a população local a descartar os resíduos e dejetos de maneira inapropriada, favorecendo o seu próprio adoecimento e à contaminação do solo e cursos hídricos do quilombo.

O indicador 'Áreas de APP' também foi considerado insustentável, devido às condições de uso e ocupação do solo na área, pois a comunidade, por vezes, necessita residir ou cultivar próximo aos cursos hídricos pela escassez de água para alimentação e agricultura, pois o quilombo não tem acesso a políticas de irrigação e água encanada, de maneira que a ocupação humana nas áreas de proteção ambiental tem provocado severos danos à biodiversidade e à manutenção da sustentabilidade local.

Ficaram evidentes os conflitos referentes ao uso e à ocupação do solo nas áreas destinadas à preservação, de maneira que o uso conflitivo mais comum se traduz nas formas de pastagem e solo exposto, que juntos ocupam $32,76 \%$ do território das APP, o que evidencia a presença de atividade antrópica nas áreas legalmente protegidas pela legislação ambiental.

Entretanto, observou-se a preocupação da comunidade com o uso sustentável da terra, uma vez que ela subsiste da terra, mantendo assim forte relação simbólica com ela, pois que os espaços são também lócus de expressão de identidade e territorialidade das comunidades. Do ponto de vista ambiental, houve preocupação em conservar as áreas de vegetação nativa e manter os mecanismos tradicionais de cultivo, não se utilizando defensivos agrícolas nas plantações, o que demonstra segurança alimentar e preocupação em retirar do solo alimentos que realmente promovam saúde e bem-estar, desta forma constata-se que os indicadores mais sustentáveis da dimensão ambiental para os quilombos foram justamente o \% de Reserva Legal' e o 'Uso de Defensivos Agrícolas'. Por fim, é necessário haver adoção de medidas de recuperação das APP, uma vez que desmatamentos e outros usos incorretos dos solos podem comprometer a sustentabilidade e qualidade de vida das comunidades quilombolas. 


\section{REFERÊNCIAS}

BARBETTA, P. A.. Estatística aplicada às ciências sociais. 7 ed. Florianópolis: UFSC, 2008.

BORGES, L. A. C.; REZENDE, J. L. P.; PEREIRA, J. A. A.; JUNIOR, L. M. C.; BARROS, D. A.. Áreas de preservação permanente na legislação ambiental brasileira. Revista Ciência Rural, Santa Maria, v.41, n.7, p.1202-1210, 2011. DOI: https://doi.org/10.1590/S0103-84782011000700016

BRASIL. Lei $\mathbf{n} .9985$ de 19 de julho de 2000. Dispõe sobre o Sistema Nacional de Unidades de Conservação da Natureza SNUC. Brasília: DOU, 2000.

BRASIL. Decreto n. 4.887, de 20 de novembro de 2003. Regulamenta o procedimento para identificação, reconhecimento, delimitação, demarcação e titulação das terras ocupadas por remanescentes das comunidades dos quilombos de que trata o art. 68 do Ato das Disposições Constitucionais Transitórias. Brasília: DOU, 2003.

BRASIL. Lei n. 11.445 de 05 de janeiro de 2007. Dispõe sobre as diretrizes nacionais para o saneamento básico; cria o Comitê Interministerial de Saneamento Básico. Brasília: DOU, 2007.

BRASIL. Lei n. 12.651 de $\mathbf{2 5}$ de maio de 2012. Dispõe sobre a proteção da vegetação nativa. Brasília: DOU, 2012.

BRASIL. Palmares, Fundação Cultural. Mapa de quilombos sergipanos. Aracaju, 2020.

CONAQ. Coordenação Nacional de Articulação das Comunidades Negras Rurais. Cadastro Ambiental Rural em Territórios Quilombolas Sem Perda de Direitos. Salvador: CONAQ, 2020.

COSTA, C. C.; GOMES, L. J.; ALMEIDA, A. P.. Selection indicators of sustainability in the Atlantic Forest fragments in basin hydrographic River Poxim through thegeoprocessing. Revista Eletrônica em Gestão, Educação e Tecnologia (REGET/UFSM), Santa Maria, v..18, n.1, p.209-219, 2014. DOI: http://dx.doi.org/10.5902/223611701124

EUGENIO, F. C.; SANTOS, A. R.; LOUZADA, F. L. R. O.; PIMENTEL, L. B.; MOULIN, J. V.. Identificação de áreas de preservação permanente no município de Alegre utilizando geotecnologia. Revista Cerne, Lavras, v.17, n.4, p.563-571, 2011. DOI: https://doi.org/10.1590/S0104$\underline{77602011000400016}$

FRIZEIRO, M. C.. Comunidade Quilombola de Serra da Guia. Coleção Terras de Quilombos de Sergipe. Belo Horizonte: FAFICH, 2016.

IANOVALI, C. A. D.; RIBEIRO FILHO, A. A.; KHATOUNIAN, C. A.. Produtividade agrícola e mudanças socioculturais: a agricultura quilombola no Vale do Ribeira - São Paulo, Brasil. Revista desenvolvimento e Meio Ambiente, Paraná, v.49, p.221-238, 2018. DOI: http://doi.org/10.5380/dma.v49i0.54697

IBGE. Instituto Brasileiro de Geografia e Estatística. Projeção da População (revisão 2018). Rio de Janeiro: IBGE, 2018.

INCRA. Instituto Nacional de Colonização e Reforma Agrária.
INCRA nos Estados: informações gerais sobre os assentamentos rurais de reforma agrária. Brasília: INCRA, 2018.

IRIGARAY, C. T. J. H.; SILVA, C. J.; NUNES, J. R. S.; MEDEIROS, H. Q.; BARROS, D. P.; SANDER, N. L.. Áreas protegidas na Amazônia mato-grossense: riscos e desafios à conservação e preservação. Novos Cadernos NAEA, Belém, v.16, n.1, p.221-246, 2013. DOI:

http://dx.doi.org/10.5801/ncn.v16i1.1440

MAPBIOMAS. Processamento Digital: canal de conteúdos GEO. MapBiomas: plataforma online mapeia uso da terra no Brasil. São Paulo: MAPBIOMAS, 2019.

MEDEIROS, M. S.; AUGUSTO, L. G. S.; BARCA, S.; SACRAMENTO, D. S.; SANTIAGO NETA, I. S. S.; GONÇALVES, I. C.; COSTA, A. M.. A saúde no contexto da reserva de desenvolvimento sustentável: o caso de Mamirauá na Amazônia Brasileira. Revista Saúde e Sociedade, São Paulo, v.27, n.1, p.128-148, 2018. DOI: https://doi.org/10.1590/S0104-12902018170514

MINAYO, M. C. S.; HATZ, Z. M. A.; BUSS, P. M.. Qualidade de vida e saúde: um debate necessário. Revista Ciência e Saúde Coletiva, Rio de Janeiro, v.5, n.1, p.7-18, 2000.

MUCELLIN, C. A.; BELLINI, M.. Lixo e impactos ambientais perceptíveis no ecossistema urbano. Revista Sociedade e Natureza, Uberlândia, v.20, n.1, p.111-124, 2008. DOI: https://doi.org/10.1590/S1982-45132008000100008

NEVES, P. S. C.. Etinicidades e lutas sociais no campo: no Brasil contemporâneo: um estudo de caso. Revista Ambivalências, Aracaju, v.4. n.7, p.68-86, 2016.

NODARY, R. O.; GUERRA, M. P.. Agroecologia: estratégias de pesquisas e valores. Revista Estudos Avançados, São Paulo, v.29, n.83, p.183-207, 2015. DOI: http://doi.org/10.1590/S0103-40142015000100010

OLIVEIRA, T. G.; FRANCISCO, C. N.. Mapeamento de Áreas de Preservação e as mudanças no Código Florestal. Revista Cadernos de Geografia, Belo Horizonte, v.28, n.53, 2018. DOI: http://doi.org/10.5752/P.2318-2962.2018v28n54p574$\underline{587}$

PHILLIPI JUNIOR, A.; SILVA NETO, A. J.. Interdisciplinaridade em ciência, tecnologia e inovação. São Paulo: Manole, 2011.

PINTO, L. V. A.; BOTELHO, S. A.; DAVIDE, A. C.; FERREIRA, E.. Estudo das nascentes da bacia hidrográfica do Ribeirão Santa Cruz, Lavras /MG. Revista Scientia Forestalis, Piracicaba, n.65, p.197-206, 2004.

RIBEIRO, J. S.; UMBELINO, L. F.; OLIVEIRA, V. P. S.. A importância dos estudos agroambientais nos territórios quilombolas no estado do Rio de Janeiro. Revista Geographia Opportuno Tempore, Londrina, v.4, n.2, p.104108, 2018.

ROCHA, C. H. B.; FREITAS, F. A.; CASQUIN, A. P.. Conflitos de uso da terra nas APPS hídricas de Manancial de Zona da Mata Mineira, Brasil. Revista Boletim Goiano de Geografia, Goiânia, v.39, p.1-11, 2019. DOI: 
https://doi.org/10.5216/bgg.v39.50021

SANTOS, F. F. S.; DALTRON FILHO, J.; MACHADO, C. T.; VASCONCELOS, J. F.. O desenvolvimento do saneamento básico no Brasil e as consequências para a saúde pública. Revista Brasileira de Meio Ambiente, Recife, v.4, n.1, p.241251, 2018.

SILVA, M. G.; CÂNDIDO, G. A.; MARTINS, M. F.. Método de construção do índice de Desenvolvimento Local Sustentável: uma análise metodológica e aplicada. Revista Brasileira de Produtos Agroindustriais, Campina Grande, v.11, n.1, p.5572, 2009.

SOBRAL, I. S.; ALMEIDA, J. A. P.; GOMES, L. J.. Indicadores de sustentabilidade e ecologia da paisagem: planejamento e gestão ambiental em assentamentos de reforma agrária.
Washington: Novas Edições Acadêmicas, 2012.

SOBRAL, I. S.; MENDES, G.. Cartografia das implicações ambientais da produção de petróleo onshore no município de Carmópolis, Sergipe, Brasil. Boletim Goiano de Geografia, Goiânia, v.35, n.3, p.437-451, 2015.

SOUZA, G. M. F.; LIMA, M. M. L.. Empreendedorismo sustentável: Estudo de caso na Associação de Agricultores de Hortifrútis Orgânicos na cidade de Juazeiro do Norte/CE. Revista Inteligência Competitiva, Santana do Parnaíba, v.10, n.1, p.16-35, 2020.

TUNDISI, J. G.; TUNDISI, T. M.. Impactos potenciais das alterações do Código Florestal nos recursos hídricos. Revista Biota Neotrópica, São Carlos, v.10, n.4, p.67-75, 2010. DOI: http://dx.doi.org/10.1590/S1676-06032010000400010

A CBPC - Companhia Brasileira de Produção Científica (CNPJ: 11.221.422/0001-03) detém os direitos materiais desta publicação. Os direitos referem-se à publicação do trabalho em qualquer parte do mundo, incluindo os direitos às renovações, expansões e disseminações da contribuição, bem como outros direitos subsidiários. Todos os trabalhos publicados eletronicamente poderão posteriormente ser publicados em coletâneas impressas sob coordenação da Sustenere Publishing, da Companhia Brasileira de Produção Científica e seus parceiros autorizados. Os (as) autores (as) preservam os direitos autorais, mas não têm permissão para a publicação da contribuição em outro meio, impresso ou digital, em português ou em tradução. 